\title{
Penerapan Metode Preference Selection Index Dalam Pemilihan Teller Terbaik
}

\author{
Muhammad Rizki, Garuda Ginting* \\ Program Studi Teknik Informatika, Universitas Budi Darma, Medan, Indonesia \\ Email: 1rizkypujakesuma69@gmail.com, 2," garuda.ginting@stmik-budidarma.ac.id
}

\begin{abstract}
Abstrak
Di era globalisasi yang sarat dengan persaingan, kualitas layanan yang baik menjadi perhatian bagi perusahaan yang ingin tetap eksis, terutama perusahaan di bidang jasa seperti Bank di Indonesia. Lembaga dengan kualitas layanan yang rendah akan kurang diminati atau bahkan ditinggalkan oleh pelanggan. Oleh karena itu, identifikasi terhadap karakteristik kualitas layanan diperlukan dalam upaya peningkatan kualitas layanan. Salah satunya teller yang paling berperan penting dalam pelayanan nasabah. Tentunya pemilihan teller terbaik harus dilakukan dengan sebaik mungkin. Berdasarkan masalah tersebut maka metode PSI digunakan dalam penelitian ini yaitu untuk penentuan teller dengan mempertimbangkan aspek-aspek penentuan yang telah ditentukan oleh pihak Bank tersebut. Adapun aspek-aspek penentuan yang menjadi dasar penentuan oleh pihak Bank dalam penentuan teller terbaik adalah sikap, skill dan penampilan. Dengan menggunakan metode PSI diharapkan dapat membantu pimpinan Bank CIMB Niaga dalam melakukan proses penentuan teller sehingga lebih cepat dan efektif. Menjadi referensi untuk penelitian yang berhubungan dengan Bank.
\end{abstract}

Kata Kunci: Teller, Preference Selection Index, Sistem Pendukung Keputusan

\begin{abstract}
In the era of globalization which is laden with competition, good service quality is a concern for companies that want to continue to exist, especially companies in the service sector such as banks in Indonesia. Institutions with low service quality will be less desirable or even abandoned by customers. Therefore, identification of service quality characteristics is needed in an effort to improve service quality. One of them is the teller who plays the most important role in customer service. Of course the selection of the best tellers must be done as well as possible. Based on these problems, the PSI method used in this study is to determine the teller by considering aspects of the determination that has been determined by the Bank. The aspects of determination which are the basis of determination by the Bank in determining the best teller are attitude, skill and appearance. By using the PSI method it is expected to be able to assist the leadership of the CIMB Niaga Bank in determining the teller process so that it is faster and more effective. Become a reference for research related to the Bank.
\end{abstract}

Keywords: Tellers; Preference Selection Index; Decision Support System

\section{PENDAHULUAN}

Kemajuan teknologi saat ini menuntut perusahaan-perusahaan harus dapat mengembangkan sumber daya teknologi sehingga mampu bersaing dan mengikuti kemajuan zaman. Kemajuan suatu perusahaan dipengaruhi oleh beberapa faktor, salah satu faktor terbesar yaitu peningkatan pelayanan perusahaan.

Bank adalah sebuah lembaga intermediasi keuangan umumnya didirikan dengan kewenangan untuk menerima simpanan uang, meminjamkan uang, dan menerbitkan promes atau yang dikenal sebagai banknote. Bank termasuk tempat dimana potensi menunggu dalam suatu garis antrian cukup besar. Agar dapat memperoleh layanan, nasabah harus antri dan menunggu. Waktu yang dihabiskan nasabah untuk menunggu giliran guna mendapatkan layanan merupakan suatu kerugian yang sebenarnya dapat menjadi lebih menguntungkan apabila dimanfaatkan untuk kegiatan yang lain. Umumnya para nasabah bersifat terbuka dan ada kecenderungan untuk minta dilayani dengan ramah, tepat pada sasaran, dan cepat.

Banyak nasabah yang tergesa-gesa melampiaskan rasa kesalnya karena pelayanan teller yang lamban, bertele-tele, dan kurang atau tidak ramah. Keadaan ini dapat menimbulkan keluhan dari para nasabah apabila penanganan yang serius terhadap proses pelayanan tidak dilakukan. Oleh karena itu, identifikasi terhadap karakteristik kualitas layanan diperlukan dalam upaya peningkatan kualitas layanan. Salah satunya teller yang paling berperan penting dalam pelayanan nasabah.

Dalam permasalahan pemilihan teller terbaik pada bank CIMB Niaga masih menggunakan sistem manual yakni dengan penunjukkan langsung oleh manager dengan melihat kinerja kerja sehari-hari oleh karyawan. Untuk mengatasi permasalahan ini maka digunakan sistem pendukung keputusan untuk memudahkan seorang pimpinan dalam pengambilan keputusan[1]. Metode yang digunakan dalam sistem pendukung keputusan ini adalah Preference Sellection Index.

Preference Sellection Index atau Metode PSI diusulkan oleh Maniya dan Bhatt pada tahun 2010 untuk menyelesaikan masalah pemilihan material MCDM. Berbeda dengan kebanyakan metode MCDM, metode PSI tidak memerlukan penentuan kepentingan relatif dari kriteria, dan oleh karena itu, tidak perlu menentukan bobot kriteria. Dengan demikian, metode ini sangat berguna dalam kasus-kasus di mana konflik dalam memutuskan kepentingan relatif di antara kriteria muncul. Sebenarnya, metode PSI menentukan bobot kriteria hanya dengan menggunakan informasi yang diberikan dalam matriks keputusan, yaitu menggunakan pendekatan obyektif untuk menentukan bobot kriteria seperti standar deviasi atau metode entropi[2]-[4]. 


\section{METODE PENELITIAN}

\subsection{Sistem Pendukug Keputusan}

Secara umum Sistem Pendukung Keputusan didefinisikan sebagai sebuah sistem yang mampu memberikan kemampuan baik kemampuan pemecahan masalah maupun kemampuan pengkomunikasian untuk masalah semiterstruktur. Secara khusus Sistem Pendukung Keputusan didefinisikan sebagai sebuah sistem yang mendukung kerja seorang manajer maupun sekelompok manajer dalam memecahkan masalah semi-terstruktur dengan cara memberikan informasi ataupun usulan menuju pada keputusan tertentu [5]-[7].

\subsection{Metode Preference Sellection Index}

Preference Sellection Index atau Metode PSI diusulkan oleh Maniya dan Bhatt pada tahun 2010 untuk menyelesaikan masalah pemilihan material MCDM. Berbeda dengan kebanyakan metode MCDM, metode PSI tidak memerlukan penentuan kepentingan relatif dari kriteria, dan oleh karena itu, tidak perlu menentukan bobot kriteria. Dengan demikian, metode ini sangat berguna dalam kasus-kasus di mana konflik dalam memutuskan kepentingan relatif di antara kriteria muncul. Sebenarnya, metode PSI menentukan bobot kriteria hanya dengan menggunakan informasi yang diberikan dalam matriks keputusan, yaitu menggunakan pendekatan obyektif untuk menentukan bobot kriteria seperti standar deviasi atau metode entropi [8]-[12]. Adapun prosedur dari preference sellection index antara lain:

1. Menghitung separation measure

2. Menentukan jarak antara nilai setiap alternatif dengan matriks solusi ideal positif dan negatif

3. Menentukan nilai preferensi untuk setiap alternatif

4. Decision matrix $\mathrm{D}$ mengacu terhadap $\mathrm{m}$ alternatif yang akan dievaluasi berdasarkan $\mathrm{n}$ kriteria yang didefinisikan sebagai berikut:

$$
D=\begin{array}{lll}
X_{11} & X_{12} & X_{1 n} \\
X_{21} & X_{22} & X_{2 n} \\
X_{m 1} & X_{m 2} & X_{m n}
\end{array}
$$

5. Dengan $\mathrm{x}_{\mathrm{ij}}$ menyatakan performansi dari perhitungan untuk alternatif ke-i terhadap atribut ke-j.

Langkah-langkah dalam penggunaan metode Preference Sellection Index antara lain:

1. Membangun normalized decision matrix

Elemen $\mathrm{r}_{\mathrm{ij}}$ hasil dari normalisasi decision matrix $\mathrm{R}$ dengam metode euclidean length of a vector adalah :

$$
R_{i j=\frac{x_{i j}}{X j^{m a x}}}
$$

Jika harapannya adalah yang lebih kecil yang lebih baik, maka kinerja atribut asli dapat dinormalisasi sebagai berikut:

$$
R{ }_{i j}=\frac{x_{j}^{\text {min }}}{X_{i j}}
$$

2. Membangun weight normalized decision matrix

Dengan bobot $\mathrm{W}=\left(\mathrm{w}_{1}, \mathrm{w}_{2} \ldots, \mathrm{w}_{\mathrm{n}}\right)$, maka normalisasi bobot matriks $\mathrm{V}$ adalah:

3. Hitung nilai variasi preferensi $(\mathrm{PVj})$. Pada langkah ini, nilai variasi preferensi $(\mathrm{PVj})$ atau setiap atribut ditentukan dengan konsep analogi varian sampel menggunakan persamaan berikut :

$$
P V_{j}=\sum_{i=1}^{n}\left[R_{i j}-\overline{R_{i j}}\right]^{2} \text {. }
$$

4. Menentukan solusi ideal positif dan solusi ideal negatif

Solusi ideal dinotasikan $\mathrm{A}^{+}$, sedangkan solusi ideal negatif dinotasikan $\mathrm{A}-$ :

$$
\begin{array}{ll}
\mathrm{A}^{+} & =\left\{\left(\max \mathrm{v}_{\mathrm{ij}} \mathrm{l} \mathrm{j} \in \mathrm{J}\right),\left(\min \mathrm{v}_{\mathrm{ij}} \mid \mathrm{j} \in \mathrm{J}^{\prime}\right)\right. \\
\mathrm{i} & =1,2,3, \ldots \mathrm{m}\}=\left\{\mathrm{V}_{1} *, \mathrm{v}_{2}{ }^{*}, \ldots, \mathrm{v}_{\mathrm{n}} *\right\} \\
\mathrm{A}^{+} & =\left\{\left(\min \mathrm{v}_{\mathrm{ij}} \mathrm{j} \in \mathrm{J}\right),\left(\max \mathrm{v}_{\mathrm{ij}} \mathrm{j} \in \mathrm{J}^{\prime}\right)\right. \\
\mathrm{i} & =1,2,3, \ldots \mathrm{m}\}=\left\{\mathrm{v}_{1}-, \mathrm{V}_{2}-, \ldots, \mathrm{v}_{\mathrm{n}^{-}}\right\} \\
\mathrm{J} & =\{\mathrm{j}=1,2,3, \ldots, \mathrm{n} \text { dan } \mathrm{j} \text { merupakan benefit criteria }\} \\
\mathrm{J}^{\prime} & =\{\mathrm{j}=1,2,3, \ldots, \mathrm{n} \text { dan } \mathrm{j} \text { merupakan costcriteria }\}
\end{array}
$$

5. Menghitung Separasi $\mathrm{S}_{\mathrm{i}}{ }^{+}$adalah jarak (dalam pandangan Euclidean) alternatif dari solusi ideal didefinisikan sebagai:

$\mathrm{S}_{\mathrm{i}}+=\sqrt{\sum_{j}^{n}=1}\left(\mathrm{v}_{\mathrm{ij}}-\mathrm{v}_{\mathrm{j}}{ }^{2}\right)^{2}$, dengan $\mathrm{i}=1,2,3, \ldots, \mathrm{m}$

dan jarak terhadap solusi negatif ideal didefenisikan sebagai:

$$
\mathrm{S}_{\mathrm{i}^{-}}=\sqrt{\sum_{j}^{n}=1\left(\mathrm{v}_{\mathrm{ij}}-\mathrm{v}_{\mathrm{j}^{-}}\right)^{2}, \text { dengan } \mathrm{i}=1,2,3, \ldots, \mathrm{m}}
$$

6. Menghitung kedekatan relatif terhadap solusi ideal 
7. Merangking alternatif

Alternatif dapat dirangking berdasarkan urutan $C_{i}^{*}$. Maka dari itu, alternatif terbaik adalah salah satu yang berjarak terpendek terhadap solusi ideal dan berjarak terjauh dengan solusi ideal negatif.

\section{ANALISA DAN PEMBAHASAN}

Analisis sistem merupakan tahap yang bertujuan untuk memahami sistem, mengetahui kekurangan sistem, dan menentukan kebutuhan sistem yang lama. Dengan menganalisis masalah dan menganalisis prosedur sistem yang sedang berjalan, maka dapat dijadikan sebagai dasar perancangan dan perbaikan pada sistem yang baru agar dapat menjadi sebuah sistem yang lebih efektif dan efesien. Adapun masalah pada Bank CIMB Niaga dalam penentuan teller terbaik adalah sebagai berikut :

1. Berdasarkan survey dari MRI (Marketing Research Indonesia), meskipun menjadi salah satu bank yang berstatus Badan Usaha Milik Negara (BUMN) yang mempunyai asset diatas diatas 50 triliun, dalam aspek kualitas pelayanan Customer Service, BRI hanya menempati peringkat ke 18 dari 19 bank yang disurvey. Sedangkan dalam aspek-aspek yang lain, seperti Satpam, Telepon, Teller, Peralatan Banking Hall, Kenyamanan Ruangan, Toilet dan ATM, peringkat CIMB Niaga selalu di posisi tiga terendah.

2. Jumlah calon teller terbaik yang sangat banyak membuat kesulitan dalam pengolahan data jika hanya menggunakan pengolahan data penilaian manual atau menggunakan aplikasi pengolahan data standar seperti Microsoft Excel.

\subsection{Penerapan Metode Preference Selection Index}

Berdasarkan masalah di atas penulis melakukan penelitian bagaimana agar penentuan teller terbaik tersebut bisa melalui mengunakan bahasa pemrograman Visual Basic.Net 2008. Sehingga dalam penilaian kriteria penentuan teller terbaik pada Bank CIMB Niaga ini penulis menggunakan metode preference sellection index sebagai metode untuk menyelesaikan masalah yang ada. Adapun contoh penggunaannya misalkan Bank CIMB Niaga ingin memilih teller terbaik dengan memperhatikan beberapa kriteria. Kriteria yang dipertimbangkan oleh manajer beserta penilainya adalah dapat dilihat pada tabel.

Tabel 1. Kriteria

\begin{tabular}{lc}
\hline \multicolumn{1}{c}{ Kriteria } & Keterangan \\
\hline Sikap & P1 \\
Skill & P2 \\
Penampilan & P3 \\
Wawancara & P4 \\
\hline
\end{tabular}

1. Sikap: Baik, Cukup, Kurang

2. Skill: Baik, Cukup, Kurang

3. Penampilan: Baik, Cukup, Kurang

4. Wawancara: Baik, Cukup, Kurang

Langkah-langkah yang harus dilakukan untuk menentukan teller terbaik yang berprestasi adalah sebagai berikut:

1. Menentukan prioritas kriteria

Langkah yang harus dilakukan dalam menentukan prioritas kriteria adalah sebagai berikut:

a. Menurut matriks perbandingan berpasangan

Pada tahap ini dilakukan penilaian perbandingan antara satu kriteria yang lain. Hasil penilaian bisa dilihat dalam Tabel 2

Tabel 2. Matriks Perbandingan Berpasangan

\begin{tabular}{lcccc}
\hline & Sikap & Skill & Penampilan & Wawancara \\
\hline Sikap & 1 & 2 & 2 & 3 \\
Skill & 0.5 & 1 & 2 & 2 \\
Penampilan & 0.5 & 0.5 & 1 & 2 \\
Wawancara & 0.33 & 0.5 & 0.5 & 1 \\
Jumlah & 2.33 & 4 & 5.5 & 8 \\
\hline
\end{tabular}

Angka 1 pada kolom Sikap baris Sikap menggambarkan tingkat kepentingnan yang sama antara Sikap dengan Sikap, sedangkan angka 2 pada kolom Skill baris Sikap menunjukan Skill sedikit lebih penting dibandingkan dengan Sikap. Angka 0.5 pada kolom Sikap baris Skillmerupakan hasil perhitungan 1/nilai pada kolom Skill baris Sikap (2). Angka yang lain diperoleh dengan cara yang sama.

b. Membuat matriks nilai kriteria

Matriks ini diperoleh dengan rumus berikut: 
Nilai baris kolom baru $=$ Nilai baris kolom lama/jumlah masing kolom lama . Hasil perhitungan bisa dilihat dalam Tabel 3.

Tabel 3. Matrks Nilai Kriteria

\begin{tabular}{ccccccc}
\hline & Sikap & Skill & Penampilan & Wawancara & Jumlah & Prioritas \\
\hline Sikap & 0.43 & 0.50 & 0.36 & 0.38 & 1.67 & 0.42 \\
Skill & 0.21 & 0.25 & 0.36 & 0.25 & 1.08 & 0.27 \\
Penampilan & 0.21 & 0.13 & 0.18 & 0.25 & 0.77 & 0.19 \\
Wawancara & 0.14 & 0.13 & 0.09 & 0.13 & 0.48 & 0.12 \\
\hline
\end{tabular}

c. Membuat matriks penjumlahan setiap baris

Matriks ini dibuat dengan mengalikan nilai prioritas pada Tabel 2 dengan matriks perbandingan berpasangan (Tabel 2).

Tabel 4. Matriks Penjumlahan Setiap Baris

\begin{tabular}{cccccc}
\hline & Sikap & Skill & Penampilan & Wawancara & Jumlah \\
\hline Sikap & 0.42 & 0.54 & 0.38 & 0.36 & 1.70 \\
Skill & 0.21 & 0.27 & 0.38 & 0.24 & 1.10 \\
Penampilan & 0.21 & 0.14 & 0.19 & 0.24 & 0.78 \\
Wawancara & 0.14 & 0.14 & 0.10 & 0.12 & 0.49 \\
\hline
\end{tabular}

d. Penghitungan rasio konsitensi

Penghitungan ini di gunakan untuk memastikan bahwa nilai rasio konsitensi $(C R)<=0.1$. Jika ternyata nilai CR lebih besar dari 0.1, maka matriks perbandingan berpasangan harus diperbaiki.

Untuk menghitung rasio konsitensi, di buat tabel seperti terlihat dalam Tabel 5.

Tabel 5. Perhitungan Rasio Konsitensi

\begin{tabular}{cccc}
\hline & Jumlah per baris & Prioritas & Hasil \\
\hline Sikap & 1.70 & 0.42 & 2.12 \\
Skill & 1.10 & 0.27 & 1.37 \\
Penampilan & 0.78 & 0.19 & 0.97 \\
Wawancara & 0.49 & 0.12 & 0.61 \\
\hline
\end{tabular}

2. Menetukan prioritas subkriteria. Penghitungan subkriteria dilakukan terhadap sub-sub dari semua kriteria.

Dalam hal ini, terdapat 4 kritria yang berarti akan ada 4 perhitungan prioritas subkriteria.

a. Menghitung kriteria subkriteria dari kriteriaSikap

Langkah-langkah yang dilakukan untuk menghitung proioritas sub kriteria dari kriteriaSikap adalah sebagai berikut,

1. Membuat matriks perbandingan berpasangan

Langkah ini seperti yang dilakukan pada langkah 1.a. hasilnya ditunjukan dalam Tabel 6.

Tabel 6. Matriks Perbandingan Berpasangan Kriteria Sikap

\begin{tabular}{cccc}
\hline & Baik & Cukup & Kurang \\
\hline Baik & 1 & 3 & 5 \\
Cukup & 0.33 & 1 & 3 \\
Kurang & 0.2 & 0.33 & 1 \\
& 1.53 & 4.33 & 9 \\
\hline
\end{tabular}

2. Membuat matriks nilai kriteria

Langkah ini seperti yang dilakukan pada langkah 1.b. perbedaannya adalah adanya tambahan kolom prioritas subkriteria pada langkah ini. Hasilnya ditunjukan pada Tabel 7.

Tabel 7. Matriks Nilai Kriteria Sikap

\begin{tabular}{ccccccc}
\hline & Baik & Cukup & Kurang & Jumlah & Prioritas & Prioritas Subkriteria \\
\hline Baik & 0.65 & 0.69 & 0.56 & 1.90 & 0.63 & 1 \\
Cukup & 0.22 & 0.23 & 0.33 & 0.78 & 0.26 & 0.41 \\
Kurang & 0.13 & 0.08 & 0.11 & 0.32 & 0.11 & 0.17 \\
\hline
\end{tabular}

Nilai pada kolom prioritas subkriteria diperoleh dari nilai prioritas pada baris tersebut dengan nilai tertinggi pada kolom prioritas.

3. Menetukan matriks penjumlahan setiap baris 
Langkah ini sama dengan dilakukan pada langkah 1.c dan ditunjukan dalam Tabel 8. setiap elemen dalam tabel inin dihitung dengan mengalikan matriks perbandingan berpasangan dengan nilai prioritas.

Tabel 8. matriks penjumlahan setiap baris kriteria Sikap

\begin{tabular}{ccccc}
\hline & Baik & Cukup & Kurang & Jumlah \\
\hline Baik & 0.63 & 0.78 & 0.53 & 1.94 \\
Cukup & 0.21 & 0.26 & 0.32 & 0.79 \\
Kurang & 0.13 & 0.09 & 0.11 & 0.32 \\
\hline
\end{tabular}

4. Penghitungan rasio konsitensi

Seperti langkah 1.d, penghitungn ini di gunakan untuk memastikan bahwa nilai rasio konsitensi $(\mathrm{CR})<=0.1$. Untuk menghitung rasio konsitensi, dibuat tabel seperti yang terlihat pada Tabel 9.

Tabel 9. Penghitungan Rasio Konsistensi

\begin{tabular}{cccc}
\hline & Baris & Prioritas & Hasil \\
\hline Baik & 1.94 & 0.63 & 2.58 \\
Cukup & 0.79 & 0.26 & 1.05 \\
Kurang & 0.32 & 0.11 & 0.42 \\
\hline
\end{tabular}

b. Menghitung prioritas subkriteria dari kriteriaSkill

Langkah-langkah yang dilakukan untuk menghitung prioritas subkriteria dari kriteria prestasi kerja sama dengan yang dilakukan dalam perhitungan prioritas subkriteria dari kriteriaSikap. Langkah-langkahnya adalah sebagai berikut:

1. Membuat matriks perbandingan berpasangan

Untuk hasilnya secara lebih jelas dapat dilihat di dalam Tabel 10. berikut ini.

Tabel 10. Matriks Perbandingan Berpasangan Kriteria Skill

\begin{tabular}{cccc}
\hline & Baik & Cukup & Kurang \\
\hline Baik & 1 & 2 & 6 \\
Cukup & 0.5 & 1 & 2 \\
Kurang & 0.17 & 0.5 & 1 \\
Jumlah & 1.67 & 3.5 & 9 \\
\hline
\end{tabular}

2. Membuat matriks nilai cerita

Hasilnya tampak pada Tabel 11

Tabel 11. Matriks Nilai Kriteria Skill

\begin{tabular}{ccccccc}
\hline & Baik & Cukup & Kurang & Baris & Prioritas & Prioritas Subprioritas \\
\hline Baik & 0.60 & 0.57 & 0.67 & 1.84 & 0.61 & 1 \\
Cukup & 0.30 & 0.29 & 0.22 & 0.81 & 0.27 & 0.44 \\
Kurang & 0.10 & 0.14 & 0.11 & 0.136 & 0.12 & 0.19 \\
\hline
\end{tabular}

3. Matriks penjumlahan tiap-tiap baris Hasilnya tampak pada Tabel 12.

Tabel 12. Matriks Penjumlahan Setiap Baris Kriteria Skill

\begin{tabular}{ccccc}
\hline & Baik & Cukup & Kurang & Jumlah \\
\hline Baik & 0.61 & 0.54 & 0.71 & 1.86 \\
Cukup & 0.31 & 0.27 & 0.24 & 0.81 \\
Kurang & 0.10 & 0.13 & 0.12 & 0.36 \\
\hline
\end{tabular}

4. Perhitungan rasio konsistensi

Hasilnya terlihat dalam Tabel 13

Tabel 13. Perhitungan Rasio Konsistensi Kriteria Skill

\begin{tabular}{cccc}
\hline & Jumlah per baris & Prioritas & Hasil \\
\hline Baik & 1.86 & 0.61 & 2.47 \\
Cukup & 0.81 & 0.27 & 1.08 \\
Kurang & 0.36 & 0.12 & 0.48 \\
\hline
\end{tabular}

c. Menghitung prioritas subkriteria dari kriteria Penampilan 
Langkah-langkah yang dilakukan untuk menghitung prioritas subkriteria dari kriteriaPenampilan sama dengan yang dilakukan dalam perhitungan prioritas subkriteria dalam kriteria Sikap. Langkahlangkahnya adalah sebagai berikut:

1. Membuat matriks perbandingan berpasangan

Hasilnya terlihat dalam Tabel 14

Tabel 14. Matriks Perbandingan Berpasangan KriteriaPenampilan

\begin{tabular}{cccc}
\hline & Baik & Cukup & Kurang \\
\hline Baik & 1 & 3 & 4 \\
Cukup & 0.33 & 1 & 3 \\
Kurang & 0.25 & 0.35 & 1 \\
Jumlah & 1.58 & 4.33 & 8 \\
\hline
\end{tabular}

2. Menentukan matriks nilai kriteria

Hasilnya terlihat dalam Tabel 15

Tabel 15. Matriks Nilai Kriteria Penampilan

\begin{tabular}{ccccccc}
\hline & Baik & Cukup & Kurang & Baris & Prioritas & Prioritas Subkriteria \\
\hline Baik & 0.63 & 0.69 & 0.50 & 1.83 & 0.61 & 1 \\
Cukup & 0.21 & 0.23 & 0.38 & 0.81 & 0.27 & 0.45 \\
Kurang & 0.16 & 0.08 & 0.13 & 0.36 & 0.12 & 0.20 \\
\hline
\end{tabular}

3. Menentukan matriks penjumlahan tiap baris Hasilnya tampak dalam Tabel 16.

Tabel 16. Matriks Penjumlahan Tiap Baris Kriteria Penampilan

\begin{tabular}{ccccc}
\hline & Baik & Cukup & Kurang & Jumlah \\
\hline Baik & 1.90 & 0.81 & 0.48 & 1.90 \\
Cukup & 0.20 & 0.27 & 0.36 & 0.83 \\
kurang & 0.15 & 0.09 & 0.12 & 0.36 \\
\hline
\end{tabular}

4. Perhitungan rasio konsistensi

Hasilnya tampak dalam Tabel 17.

Tabel 17. Perhitungan Rasio Konsistensi Kriteria Penampilan

\begin{tabular}{cccc}
\hline & Jumlah Per Baris & Prioritas & Hasil \\
\hline Baik & 1.90 & 0.61 & 2.51 \\
Cukup & 0.83 & 0.27 & 1.10 \\
Kurang & 0.36 & 0.12 & 0.48 \\
\hline
\end{tabular}

d. Menghitung prioritas subkriteria dari kriteria pelaku

Langkah-langkah yang dilakukan untuk menghitung prioritas subkriteria dari kriteriaWawancara sama dengan yang dilakukan dalam perhitungan prioritas subkriteria dari kriteria kedisiplin. Langkahlangkahnya adalah sebagai berikut:

1. Menghitung matriks perbandingan berpasangan

Hasilnya tampak dalam tabel 18

Tabel 18. Matriks Perbandingan Berpasangan Kriteria Pelaku

\begin{tabular}{cccc}
\hline & Baik & Cukup & Kurang \\
\hline Baik & 1 & 2 & 5 \\
Cukup & 0.5 & 1 & 4 \\
Kurang & 0.2 & 0.25 & 1 \\
Jumlah & 1.7 & 3.25 & 10 \\
\hline
\end{tabular}

2. Menghitung matriks nilai kriteria Hasilnya terlihat dalam Tabel 19.

Tabel 19. Matriks Nilai Kriteria Wawancara

\begin{tabular}{ccccccc}
\hline & Baik & Cukup & Kurang & Baris & Prioritas & Prioritas Subkriteria \\
\hline Baik & 0.59 & 0.62 & 0.50 & 1.70 & 0.57 & 1 \\
Cukup & 0.29 & 0.31 & 0.40 & 1.00 & 0.33 & 0.59 \\
Kurang & 0.12 & 0.08 & 0.10 & 0.29 & 0.10 & 0.17 \\
\hline
\end{tabular}


3. Menghitung matrik penjumlahan tiap baris Hasilnya tampak dalam Tabel 20.

Tabel 20. Matriks Penjumlahan Tiap Baris Kriteria Wawancara

\begin{tabular}{ccccc}
\hline & Baik & Cukup & Kurang & Jumlah \\
\hline Baik & 0.57 & 0.67 & 0.49 & 1.37 \\
Cukup & 0.28 & 0.33 & 0.39 & 1.01 \\
Kurang & 0.11 & 0.08 & 0.10 & 0.30 \\
\hline
\end{tabular}

4. Perhitungan rasio konsistensi Hasilnya tampak dalam Tabel 21.

Tabel 21. Perhitungan Rasio Kompetensi Kriteria Pelaku

\begin{tabular}{cccc}
\hline & Jumlah PerBaris & Prioritas & Hasil \\
\hline Baik & 1.73 & 0.57 & 2.29 \\
Cukup & 0.01 & 0.33 & 1.34 \\
Kurang & 0.30 & 0.10 & 0.39
\end{tabular}

3. Menghitung hasil

Prioritas hasil perhitungan pada langkah 1 dan 2 kemudian dituangkan dalam matriks hasil yang terlihat dalam Tabel 22.

Tabel 22. Matriks Hasil

\begin{tabular}{cccc}
\hline Sikap & Skill & Peng. Kerja & Wawancara \\
\hline 0.42 & 0.27 & 0.19 & 0.12 \\
Baik & Baik & Baik & Baik \\
1 & 1 & 1 & 1 \\
Cukup & Cukup & Cukup & Cukup \\
0.41 & 0.44 & 0.45 & 0.59 \\
Kurang & Kurang & Kurang & Kurang \\
0.17 & 0.19 & 0.2 & 0.17 \\
\hline
\end{tabular}

Seandainya diberikan data nilai dari 3 orang teller terbaik seperti yang terlihat dalam Tabel 23, maka hasil akhirnya akan tampak dalam Tabel 24

Tabel 23. Nilai Teller

\begin{tabular}{ccccc}
\hline & Sikap & Skill & Peng. Kerja & Wawancara \\
\hline Intan & Cukup & Cukup & Baik & Baik \\
Putri & Baik & Kurang & Cukup & Cukup \\
Vindy & Cukup & Baik & Baik & Baik \\
\hline
\end{tabular}

Tabel 24. hasil akhir

\begin{tabular}{cccccc}
\hline & Sikap & Skill & Peng. Kerja & Wawancara & Total \\
\hline Intan & 0.17 & 0.12 & 0.19 & 0.12 & 0.60 \\
Putri & 0.42 & 0.05 & 0.08 & 0.07 & 0.63 \\
Vindy & 0.17 & 0.27 & 0.19 & 0.12 & 0.75 \\
\hline
\end{tabular}

Nilai 0.17 pada kolom Sikap baris Intan diperoleh dari nilai teller Intan untuk Sikap, yaitu cukup dengan prioritas 0.41 (Tabel 23). dikalikan dengan prioritas Sikap sebesar 0.42 (Tabel 23). Kolom total pada Tabel 24 diperoleh dari penjumlahan pada masing-masing barisnya. Nilai total inilah yang dipakai sebagai dasar untuk merangking prestasi teller. Semakin besar nilainya, teller tersebut akan smakin berprestasi. Jadi yang paling dominan untuk ditentukan sebagai tellera terbaik dalah Vindy.

\section{KESIMPULAN}

Berdasarkan hasil dari penelitian, diperoleh kesimpulan proses penentuan teller terbaik pada Bank CIMB Medan menggunakan aspek-aspek penilaian seperti sikap, skill, penampilan, dan wawancara. Untuk mengimplementasikan metode PSI dalam penentuan teller pada Bank CIMB Medan dilakukan mendefinisian masalah dan menentukan solusi.

\section{REFERENCES}


[1] Kusrini, Konsep dan Aplikasi Sistem Pendukung Keputusan. 2007.

[2] R. Khorshidi and A. Hassani, "Comparative analysis between TOPSIS and PSI methods of materials selection to achieve a desirable combination of strength and workability in Al/SiC composite," Mater. Des., vol. 52, no. June, pp. 999-1010, 2013.

[3] Mesran, K. Tampubolon, R. D. Sianturi, F. T. Waruwu, and A. P. U. Siahaan, "Determination of Education Scholarship Recipients Using Preference Selection Index," Int. J. Sci. Res. Sci. Technol., vol. 3, no. 6, pp. 230-234, 2017.

[4] M. K. Siahaan, M. Mesran, S. A. Hutabarat, and J. Afriany, "Sistem Pendukung Keputusan Penentuan Prioritas Pembangunan Daerah Menerapkan Metode Preference Selection Index (Psi)," KOMIK (Konferensi Nas. Teknol. Inf. dan Komputer), vol. 2, no. 1, pp. 370$375,2018$.

[5] T. Limbong et al., Sistem Pendukung Keputusan: Metode \& Implementasi. Medan: Yayasan Kita Menulis, 2020.

[6] D. Nofriansyah and S. Defit, Multi Criteria Decision Making (MCDM) pada Sistem Pendukung Keputusan. 2018.

[7] D. Nofriansyah, Konsep Data Mining Vs Sistem Pendukung Keputusan. 2015.

[8] H. C. P. Siti Aisyah, "Sistem Pendukung Keputusan Pemilihan Oli Sepeda Motor Matic Terbaik Menerapkan Metode Preference Selection Index."

[9] S. H. Sahir et al., "The Preference Selection Index method in determining the location of used laptop marketing," Int. J. Eng. Technol., vol. 7, no. 3.4 Special Issue 4, 2018 .

[10] M. Mesran, N. Huda, S. N. Hutagalung, K. Khasanah, and A. Iskandar, "Sistem Pendukung Keputusan Pemilihan Supervisor Terbaik Pada Bagian Perencanaan Pt. Pln (Persero) Area Medan Menerapkan Preference Selection Index," KOMIK (Konferensi Nas. Teknol. Inf. dan Komputer), vol. 2, no. 1, pp. 403-409, 2018.

[11] M. Madić, J. Antucheviciene, M. Radovanović, and D. Petković, "Determination of laser cutting process conditions using the preference selection index method," Opt. Laser Technol., vol. 89, no. October 2016, pp. 214-220, 2017.

[12] B. Vahdani, S. M. Mousavi, and S. Ebrahimnejad, "Soft computing-based preference selection index method for human resource management," J. Intell. Fuzzy Syst., vol. 26, no. 1, pp. 393-403, 2014. 